\title{
A brief history of medical education and training in Australia
}

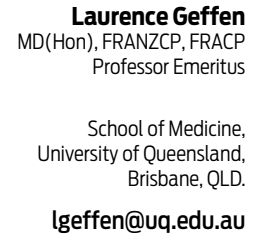

doi: 10.5694/mjal4.00118

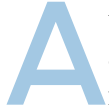
t Federation, Australia had three medical schools and no institutions for subsequent training. Now medical education and training in Australia comprises four phases: basic education provided by medical schools, prevocational training organised by postgraduate medical councils (PMCs), vocational training delivered by specialist medical colleges and continuing professional development (CPD) also conducted by the colleges.

This article describes the development of each of these phases of medical education and training over the past century and how accreditation mechanisms were established to assess and improve their quality.

\section{Basic medical education}

Basic medical education in Australia is provided by 18 medical schools, enrolling about 16000 medical students, of whom about 3000 graduate annually. ${ }^{1}$ The establishment dates of Australian medical schools, clustered into three epochs, are shown in Box 1.

\section{0 s to the 1960 s}

The first epoch, from the 1860s to the 1960s, was characterised by a gradual shift from colonial and postcolonial dependency on the United Kingdom towards self-sufficiency. Beginning with the University of Melbourne in 1862, six medical schools were established, one in each state. In the early 1960s, Victoria and New South Wales each established a second school.

Basic medical education was shaped predominantly by the requirements of the UK General Medical Council (GMC), whose accreditation authority was used to register Australian medical graduates in Australia, the UK and some other Commonwealth countries. The historical factors that influenced GMC policy are described elsewhere. ${ }^{2,3}$ Of particular note were the ideas of American educationalist, Abraham Flexner, who advocated a twophase curriculum, consisting of medical scientific disciplines followed by clinical teaching in hospital-based academic departments. ${ }^{4}$

By the 1950s, medical education in the UK had evolved from a chaotic mix of institutions and practices to its modern form, shaped in particular by the landmark 1944 Report of the inter-departmental committee on medical schools. This report recommended that medical schools be based in universities, and that teaching hospitals be equipped with academic departments in the major medical specialties. ${ }^{5}$

All Australian medical schools adopted the UK format, becoming respected institutions whose graduates were widely sought after (and often retained), when they went overseas for further training. As in the UK, Australian medical students were selected on the basis of their secondary school performance and undertook a disciplineoriented curriculum with an emphasis on factual content and elementary clinical skills. Basic sciences were taught in 1st year, preclinical sciences in 2nd year and paraclinical

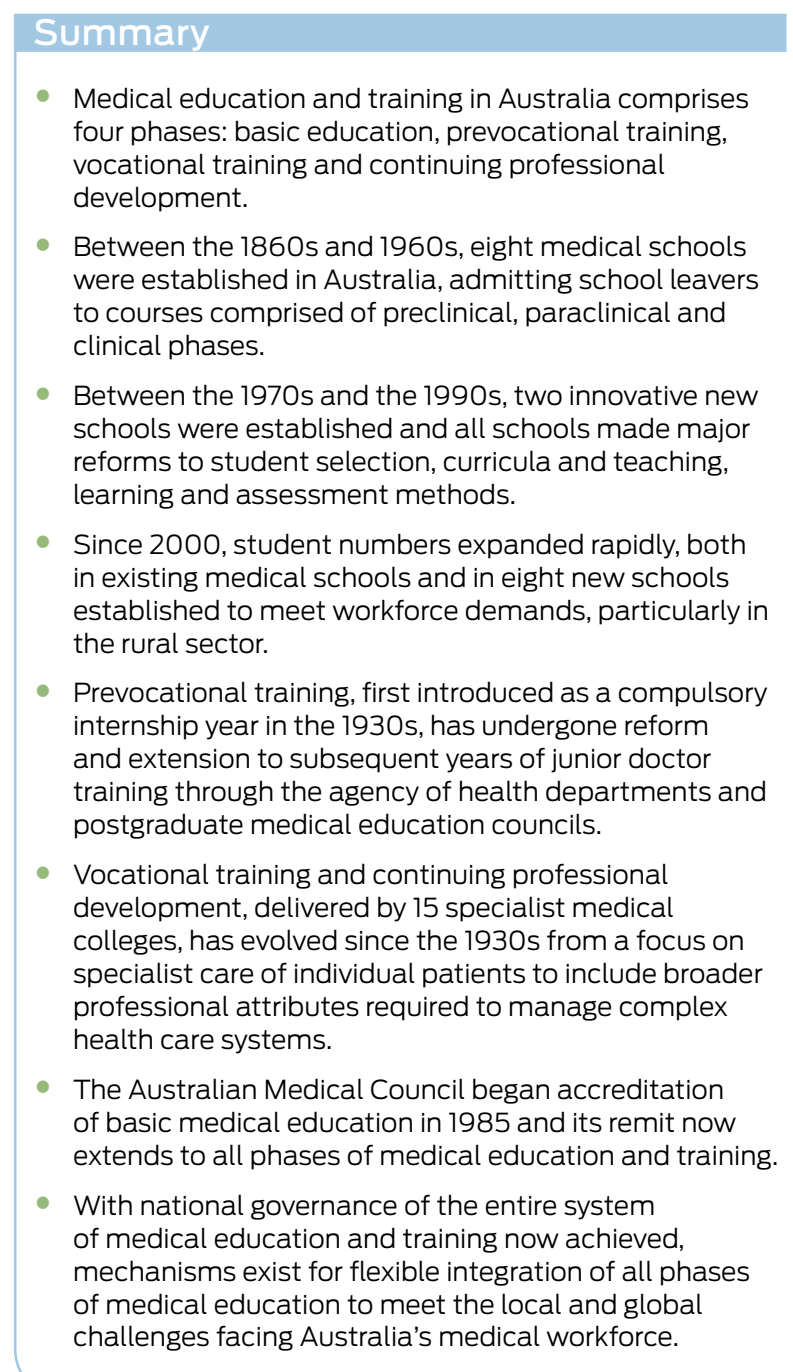

sciences and introductory clinical sciences in the 3rd and 4 th years. The final 2 years comprised clinical teaching of hospital-based specialties.

\section{0 s to the 1990s}

The second epoch began in the early 1970s. It was triggered by the 1973 Report of the Committee on Medical Schools to the Australian Universities Commission. ${ }^{6}$ To meet increased demand for medical services, the report recommended expanding the intake of existing schools and establishing several new schools; however, only the University of Newcastle medical school proceeded (the school at Flinders University had been given the go-ahead before the report and so did not form part of the recommendations, but only commenced to take students in 1974). The report also recommended additional financial support for emerging disciplines, such as community health and clinical pharmacology, and advocated the introduction of more innovative admission and educational policies. 


\begin{tabular}{lc}
1 Commencement dates of Australian medical schools* \\
Australian medical schools & $\begin{array}{c}\text { Year } \\
\text { commenced }\end{array}$ \\
\hline 1860s to the 1960s & 1862 \\
University of Melbourne & 1883 \\
University of Sydney & 1885 \\
University of Adelaide & 1936 \\
University of Queensland & 1957 \\
University of Western Australia & 1961 \\
Monash University & 1961 \\
University of New South Wales & 1965 \\
University of Tasmania & \\
1970s to the 1990s & 1974 \\
Flinders University & 1978 \\
University of Newcastle & \\
2000 onwards & 2000 \\
James Cook University & 2004 \\
Australian National University & 2005 \\
Griffith University & 2005 \\
University of Notre Dame (Fremantle) & \\
Bond University & 2006 \\
University of Western Sydney & 2007 \\
University of Wollongong & 2007 \\
Deakin University & 2008 \\
University of Notre Dame (Sydney) & \\
\hline * Source: Medical Deans Australia and New Zealand Inc. †Counted as \\
campuses of a single medical school.
\end{tabular}

Before Newcastle, only one new school, Flinders, had commenced in the preceding decade. Uniquely, the Flinders school was wholly embedded in a teaching hospital, with academics heading all clinical service departments and all hospital clinical staff having academic responsibilities. Student selection drew on a wider pool of applicants than school leavers, and the curriculum was based on vertical and horizontal integration of body systems. Newcastle then introduced other important innovations such as problem-based learning and expansion of community-based teaching.

In 1988, a federal report, Australian medical education and workforce into the 21st century, provided a spur for further reforms. Its 105 recommendations generated a surge of initiatives in all phases of medical education and training, even though it was never formally adopted by government. ${ }^{7}$

In the 1990s, another major reform occurred, with the introduction of graduate-entry, 4-year programs similar to those in North America. The first was at Flinders University in 1996, followed a year later by the Universities of Sydney and Queensland.8,9

These graduate programs led, in turn, to other widespread innovations, with an emphasis on self-directed learning guided by formative assessment. Instead of relying solely on secondary school performance, a combination of student selection procedures (including interviews, national admission tests and grade point averaging of previous university studies) was used by graduate-entry schools, by schools admitting only secondary school leavers and by schools with several types of entry. ${ }^{10}$

By the end of the 20th century, all schools had introduced redesigned courses with some horizontal (within-year) and vertical (between-year) integration of disciplines, with an emphasis on student-centred learning. Course objectives were specified within the domains of "knowledge", "skills" and "attitudes". Assessment methods were diversified with increased emphasis on formative assessment.

These sweeping reforms of traditional teaching and learning methods, curriculum content and admission procedures elicited considerable controversy within the profession, particularly among surgeons and anatomists. Concerns were expressed about erosion of admission standards and neglect of scientific knowledge, especially anatomy. "Why fix an unbroken system?" was an oft-heard refrain. An ensuing federal government enquiry reviewed the issues, but failed to report on them publicly. However, these controversies did not stem the wave of innovation transforming a uniform traditional system of basic medical education into a highly diversified one. ${ }^{11}$

sweeping reforms of traditional teaching and learning methods, curriculum content and admission procedures elicited considerable controversy 2

\section{0 onwards}

The third and current epoch, characterised by a rapid expansion of medical schools and associated rural clinical schools, was driven mainly by workforce considerations, such as shortages and maldistribution of doctors. Starting with James Cook University in 2000, eight new schools commenced within a decade, and 17 rural clinical schools were attached to both new and existing schools. ${ }^{12}$

As the number of schools almost doubled, and their graduates nearly trebled, further diversification in student demographics occurred. Women now outnumbered men and one in five students had a rural background. ${ }^{12-14}$ The increase in graduating numbers has, in turn, created stresses on resources for subsequent phases of training, especially the availability of prevocational and vocational training posts, and of clinical supervisors.

\section{Prevocational training}

Prevocational training currently comprises a compulsory intern year for about 3500 new graduates and several subsequent years of informal training of an equivalent number of junior doctors, who have not yet entered vocational training programs. ${ }^{1}$ Prevocational training is delivered by the state- and territory-based PMCs (Box 2).

Whereas in North America and Europe, medical school graduates proceed directly to vocational training as "residents", the requirement in Australia for a mandatory internship year is a legacy of the British system. Internship, gradually introduced by state and territory medical registration boards between the 1930s and 1970s, was initially intended to be a period of apprenticeship with little formal educational structure, when junior doctors progressed under supervision from "knowing" to "doing".

From the 1980s, when responsibility for prevocational training was first delegated to PMCs, prevocational training gradually acquired a framework consonant with its function of linking the basic and vocational phases of training. The fragmented administration of prevocational training into eight jurisdictions hindered progress. However, the Confederation of Postgraduate Medical Education Councils, despite lacking any legislative authority, did 
2 Establishment dates of Australian postgraduate medical councils*

Postgraduate medical councils ${ }^{\dagger}$

Postgraduate Medical Education Council of Queensland

Health Education and Training Institute (New South Wales)

South Australian Medical Education and Training

Postgraduate Medical Council of Western Australia

Postgraduate Medical Education Council of Tasmania

Postgraduate Medical Council of Victoria

Northern Territory Postgraduate Medical Council

Canberra Region Medical Education Council

* Source: Confederation of Postgraduate Medical Education Councils tCurrent names.

develop an Australian Curriculum Framework for Junior Doctors in $2010 .^{15}$ In line with developments in basic education and vocational training, this framework was designed to enhance self-directed learning, particularly in the domains of clinical management, professionalism and communication.

\section{Vocational training}

Postgraduate vocational training is currently provided by 15 medical colleges for about 13000 trainees (Box 3). ${ }^{1}$ The involvement of the colleges in postgraduate training began with the establishment of the Royal Australasian College of Surgeons in 1927. At first, vocational training was confined to tertiary teaching hospitals. However, as the numbers seeking training and the variety of training posts needed exceeded the capacity of the public hospital sector, it became necessary to extend into the private and community sectors, particularly when general practice became a recognised vocational specialty.

Initially, vocational training focused on acquiring the expert knowledge and skills necessary for the specialist clinical care of individual patients. While these remain core components, there was also a growing recognition of the wider professional responsibilities of doctors in complex health care systems.

In 1984, the Association of American Medical Colleges issued an influential report, Physicians for the twenty-first century, which focused attention on a common foundation of knowledge, skills, values and attitudes needed by all doctors - regardless of specialty. ${ }^{16}$ Fifteen years later, in 1996, the Royal College of Physicians and Surgeons of Canada developed the innovative CanMEDS Physician Competency Framework, which describes the knowledge, skills and abilities of specialists in seven domains - as medical experts, communicators, collaborators, managers, health advocates, scholars and professionals. ${ }^{17}$ CanMEDS, updated in 2005 and due for further revision in 2015, attempts to specify the common core competencies to which modern medical education and training should be directed.

At first, these North American developments only slowly influenced vocational training in Australia, but later, as accreditation mechanisms were implemented (see below), they were more fully embraced. However, they also generated considerable debate about the extent to which complex professional competencies, involving tacit and explicit knowledge, skills and attitudes, could be reduced to subsets

of highly specified competencies, as in trade vocational education.

Another recent transformation has been the shift in the emphasis of assessment from summative knowledge-based examinations at end of training to continuous workplacebased assessment of performance, both formative and summative. ${ }^{18}$ Despite its merits, performance-based assessment is a resource-intensive method for a training system already under strain from expansion in the number of trainees and a shortage of supervisors.

\section{Continuing professional development}

About 90000 registered medical practitioners are currently required to undertake $\mathrm{CPD}$, the fourth and final phase of medical education and training. ${ }^{1}$

Until the advent of the National Registration and Accreditation Scheme for health professionals in 2010, $\mathrm{CPD}$ was regarded as a laudable but voluntary activity provided by a wide range of organisations. Most colleges had introduced voluntary CPD programs, but often encountered resistance from their members to any formalisation and monitoring. Only the Royal Australian and New Zealand College of Obstetricians and Gynaecologists had made it a condition of ongoing college fellowship. The Health Practitioner National Law Act 2009 settled the issue by making CPD a condition of ongoing registration for all health professionals.

\section{Accreditation of medical education and training}

Probably the single most important influence on medical education and training has been accreditation by the Australian Medical Council (AMC). The AMC was established in 1985 after 70 years of procrastination and intermittent tortuous negotiations between state and federal governments, state and territory registration boards,

\section{Establishment dates of Australian medical colleges*}

\section{Australian medical colleges}

Royal Australasian College of Surgeons

Royal Australasian College of Physicians

Royal Australian and New Zealand College of Radiologists

Royal College of Pathologists of Australasia

Royal Australian College of General Practitioners

Royal Australian and New Zealand College of Psychiatrists

Australasian College of Dermatologists

Royal Australian College of Medical Administrators

Royal Australian and New Zealand College of Ophthalmologists

Australasian College for Emergency Medicine

Australian and New Zealand College of Anaesthetists

Australian College of Rural and Remote Medicine

Royal Australian and New Zealand College of Obstetricians and Gynaecologists

Australasian College of Sports Physicians

College of Intensive Care Medicine of Australia and New Zealand

* Source: Committee of Presidents of Medical Colleges. †Current names.
Year commenced

1927

1938

1949

1956

1958

1963

1966

1967

1969

1984

1992

1997

1998

1999

2008 
universities and various professional bodies. All share responsibility for, at some stage, placing their parochial interests in the way of a national approach. ${ }^{19}$

At first the AMC focused its accreditation activities on basic medical education, and the AMC's standards underwent several iterations over the next 25 years. ${ }^{20}$ Despite early apprehension, AMC accreditation has since been accepted by medical schools (including those in New Zealand) as operating impartially, collegially and in accordance with defensible standards and processes. This approach has fostered innovation and flexibility by respecting university autonomy and encouraging a diversity of approaches. Above all, its focus has been on quality improvement rather than just on the achievement of minimal standards.

The AMC made sporadic attempts since its inception to apply national standards to prevocational training, only to be frustrated by the existing jurisdictions. ${ }^{20}$ When the Medical Board of Australia replaced the state and territory boards in 2010, it referred accreditation of prevocational training to the AMC. The AMC is in the process of establishing a national accreditation system whereby PMCs, which accredit their local training posts, are themselves subject to "meta-accreditation" by the AMC. This should enable prevocational training to be better linked nationally to basic education and vocational training.

Until 2001, there was no mechanism for accrediting vocational training, other than cursory oversight by the National Specialist Qualification Advisory Committee, a Commonwealth body established in 1972 and abolished in 2001. The AMC then undertook accreditation of vocational training and CPD programs. ${ }^{20}$ Like medical schools before them, some colleges were reluctant to cede any aspect of autonomy to the AMC. The threat of action by the Australian Competition and Consumer Commission against "closed shops" soon changed their minds. As was the case with basic education, AMC accreditation of vocational training has helped bring about a much needed improvement in the quality of vocational training and its responsiveness to the ever-changing needs of the health sector, including the complex multiple roles now required of specialists beyond that of individual patient care.

\section{International developments}

Between 1997 and 2003, the World Federation for Medical Education developed global standards for quality improvement of basic medical education, postgraduate medical education and CPD. ${ }^{21-23}$ The AMC participated in the formulation and implementation of these global standards and was actively involved in developing regional and national specifications of the standards through the Association for Medical Education in the Western Pacific Region.

Since 1992, the AMC has accredited New Zealand medical schools on behalf of the Medical Council of New Zealand. The AMC also covers much of vocational training in New Zealand through its accreditation of binational specialist colleges. In addition to New Zealand, other countries in the region, China in particular, now use Australia as a benchmark for their medical education reforms. Since 2000, Chinese authorities have based the implementation of their accreditation system on AMC policies and procedures. ${ }^{20}$
Over the past 150 years, Australia has acquired an internationally respected medical education and training system. Each of the four phases developed independently and asynchronously, driven intermittently by advances in pedagogy and by workforce demands, and at times hindered by the medical politics of each epoch.

National governance of the entire system of medical education and training has only recently been achieved, with the Medical Board of Australia setting registration requirements and the $\mathrm{AMC}$ implementing accreditation standards. Mechanisms are now in place, for the first time, for integration of all phases of medical education to meet the local and regional challenges facing Australia's medical workforce.

Acknowledgements: I thank Peter Arnold and Michael Field for their valued advice.

Competing interests: I was the Dean of Medicine at Flinders University from 1985 to 1988, Dean of Medicine at the University of Queensland from 1991 to 1994, member of the Australian Medical Council from 1988 to 2000 and chair of its Accreditation Committee from 1996 to 2000.

Provenance: Commissioned; externally peer reviewed

1 Australian Institute of Health and Welfare. Medical Workforce 2011. Canberra: AlHW, 2013. (AlHW Cat. No. HWL 49.) http://www.aihw.gov.au/publication-detail/?id=60129542627 (accessed May 2014).

2 Milnes Walker R. Medical education in Britain. London: Nuffield Provincial Hospitals Trust, 1965.

3 Sinclair D. Basic medical education. London: Oxford University Press, 1972.

4 Flexner, A. Medical education: a comparative study. New York: Macmillan, 1925.

5 Report of the Interdepartmental Committee on Medical Schools. London: HMSO, 1944.

6 Australian Universities Commission Committee on Medical Schools. Expansion of medical education: report of the Committee on Medical Schools to the Australian Universities Commission. Canberra: Australian Government Publishing Service, 1973.

7 Committee of Inquiry into Medical Education and Medical Workforce. Australian medical education and workforce into the 21st century. Canberra: Australian Government Publishing Service, 1988.

8 Geffen LB. The case for graduate schools of medicine in Australia. Med J Aust 1991; 155: 737-740.

9 Geffen L, Saunders N, Sefton A. Australian graduate medical schools. A progress report. Med J Aust 1994; 160: 393-394.

10 Rolfe IE, Pearson S, Powis DA, Smith AJ. Time for a review of admission to medical school? Lancet 1995; 346: 1329-1333.

11 Lawson M, Bearman M. Medical education in Australia: what makes for success? Summary report: surveys, focus groups and interviews. Canberra: Department of Education Science and Training, 2007. http://www.innovation.gov.au/HigherEducation/ResourcesAndPublications/Documents/HEReports/ AMES-8.rtf (accessed Nov 2013).

12 Medical Deans Australia and New Zealand. Medical schools - current and proposed: fact sheet. http:// www.medicaldeans.org.au/medical-schools-current-and-proposed-fact-sheet.html (accessed Nov 2013).

13 Worley P, Silagy C, Prideaux D, et al. The Parallel Rural Community Curriculum: an integrated clinical curriculum based in rural general practice. Med Educ 2000; 34: 558-565.

14 Brooks PM, Lapsley HM, Butt DB. Medical workforce issues in Australia: “tomorrow's doctors -- too few, too far". Med J Aust 2003; 179: 206-208.

15 Confederation of Postgraduate Medical Education Councils. Australian Curriculum Framework for Junior Doctors. http://www.cpmec.org.au/Page/acfjd-project (accessed Nov 2013).

16 Panel on the General Professional Education of the Physician and College Preparation for Medicine. Physicians for the twenty-first century. Washington: Association of American Medical Colleges, 1984.

17 Royal College of Physicians and Surgeons of Canada. CanMEDS 2005 Framework. http://www. royalcollege.ca/portal/page/portal/rc/common/documents/canmeds/framework/the_7_canmeds_ roles_e.pdf (accessed Nov 2013).

18 Australian Medical Council. Competence-based medical education. AMC consultation paper. 2010. http://www.amc.org.au/images/publications/CBEWG_20110822.pdf (accessed Nov 2013).

19 Livingstone P. Birth of the Australian Medical Council. In: Geffen L, editor. Assuring medical standards: the Australian Medical Council 1985-2010. Canberra: AMC, 2010: 1-10.

20 Geffen L, editor. Assuring medical standards: the Australian Medical Council 1985-2010. Canberra: AMC, 2010: 33-60.

21 World Federation for Medical Education. Global standards for quality improvement: basic medical education. Copenhagen: WFME, 2003.

22 World Federation for Medical Education. Global standards for quality improvement: postgraduate medical education. Copenhagen: WFME, 2003.

23 World Federation for Medical Education. Global standards for quality improvement: continuing professional development of medical doctors. Copenhagen: WFME, 2003. 